\title{
Comparison of efficacy of add-on therapy of vildagliptin versus pioglitazone among Type 2 diabetes mellitus patients inadequately controlled on dual therapy of metformin plus sulfonylurea
}

\author{
Kirandeep Kaur', Rupinder Kaur², Naveen Mittal' ${ }^{3}$, Shalini Arora', Sandeep Kaushal' \\ ${ }^{1}$ Department of Pharmacology, Dayanand Medical College and Hospital, Ludhiana, India, ${ }^{2}$ Department of Pharmacology, DY Patil Medical \\ College \& Hospital, Navi Mumbai, India, ${ }^{3}$ Department of Endocrinology, Dayanand Medical College and Hospital, Ludhiana, India
}

\section{A B S T R A C T}

Objectives: To compare the efficacy of add on therapy of Vildagliptin versus Pioglitazone among Type 2 Diabetes Mellitus patients inadequately controlled on dual therapy of metformin and sulfonylureas. Methods: This was an open label prospective non randomized trial conducted on 50 patients attending Endocrinology Outpatient Department in a tertiary care hospital. Patients with type 2 Diabetes Mellitus (Type 2 DM) with age between 30 to 70 years of either gender, on dual oral anti-diabetic treatment (Metformin + Sulfonylurea) for at least last 3 months; $\mathrm{HbA}_{1 \mathrm{c}}>7 \%$ and $<11 \%$, $\mathrm{BMI}>25 \mathrm{~kg} / \mathrm{m}^{2}$, were included. Group I patients were started on pioglitazone (30 $\mathrm{mg}$ once daily) and those in group II started on vildagliptin (50 mg twice daily), in addition to their earlier treatment of metformin and sulfonylurea. Primary end point was change in $\mathrm{HbA}_{1 \mathrm{c}}$ levels after 12 weeks from baseline and secondary outcomes were change from baseline in fasting plasma glucose (FPG) levels and percentage of patients with endpoint $\mathrm{HbA}_{1 \mathrm{c}}<7 \%$ at 12 weeks. Results: A significant fall in $\mathrm{HbA}_{1 \mathrm{c}}$ levels was seen in both the groups after 12 weeks of treatment with metformin, sulfonylureas and pioglitazone/ vildagliptin $(\mathrm{p}<0.001)$, however the decrease in $\mathrm{HbA}_{1 \mathrm{c}}$ levels at 12 weeks were not statistically different between the two groups $(p=0.16)$. Only four patients out of a total of 50 , showed $\mathrm{HbA}_{1 \mathrm{c}}<7 \%$ at 12 weeks, out of which three were from pioglitazone and one patient from vildagliptin group. The FPG and random plasma glucose levels also decreased significantly in both the groups ( $p<0.001$ ). No adverse effect was reported by the patients. Conclusion: Both vildagliptin and pioglitazone provided additional $\mathrm{HbA}_{1 \mathrm{c}}$ lowering to that achieved with metformin and sulfonylurea. Vildagliptin demonstrates similar efficacy and safety to pioglitazone when added to metformin and sulfonylureas for three months. The clinical study is registered with Clinical Trials Registry of India, no. CTRI/2013/04/003582.

Access this article online

Website:

http://nepjol.info/index.php/AJMS

Key words: Pioglitazone, vildagliptin, glycosylated hemoglobin

\section{INTRODUCTION}

The prevalence of type 2 diabetes mellitus (Type $2 \mathrm{DM}$ ) is a global public health threat. According to the International Diabetes Federation there are 382 million people having diabetes in 2013 and by year 2035 this will rise to 592 million. ${ }^{1}$ While Type $2 \mathrm{DM}$ poses a huge financial burden on all nations, developing countries bear the highest burden as more than $80 \%$ of cases occur in these countries. ${ }^{2}$
Prevalence estimates of DM and impaired glucose tolerance (IGT) are high in all Asian countries and are expected to grow further in the next two decades. The current trend indicates that more than $60 \%$ of the total world's total population with type $2 \mathrm{DM}$ will live in Asia. ${ }^{2}$ By year 2025, approximately 57.2 million Indians will be affected by this disease. ${ }^{3}$ Urbanization and socio-economic progress are important factors for the increase in the prevalence of DM in the last two or three decades. ${ }^{2}$ 
Type $2 \mathrm{DM}$ is a progressive disease and monotherapy often fails after a certain duration of treatment leading to a scenario where use of combination of drugs becomes necessary for optimal glycemic control. ${ }^{4}$ According to the American Diabetes Association (ADA) 2012 guidelines, metformin is the drug of first choice in care of type $2 \mathrm{DM}^{5}$ If target levels of glycosylated hemoglobin $\left(\mathrm{HbA}_{1 c}\right)$ are not achieved/maintained after approximately three months of treatment with metformin, then one of the five treatment options can be combined with metformin i.e. a sulfonylurea or a thiazolidinedione (TZD), or a Dipeptidylpeptidase-4 (DPP-4) inhibitor, or a Glucagon like peptide-1(GLP-1) receptor agonist or basal insulin. ${ }^{5}$ The addition of third non-insulin drug has shown benefit over the dual combination therapy among the patients not achieving the target glycemic control. The recommendations provide a choice among the thiazolidinediones or DPP-4 inhibitors or GLP-1 receptor agonist or insulin as the third add-on option in such patients. ${ }^{5}$

Pioglitazone, a thiazolidinedione, is a ligand for the peroxisome proliferator-activated receptor gamma (PPAR- $\gamma$ ), a group of nuclear receptors which are involved in the regulation of genes related to lipid and glucose metabolism. ${ }^{6}$ Pioglitazone is known to reduce vascular risk and inflammatory markers, and improve carotid intima media thickness independent of its glycemic effect. ${ }^{7}$ The results of PROactive17 trial show that addition of pioglitazone to an existing dual oral therapy regimen of metformin-sulphonylurea combination resulted in sustained improvements in glycemic control and reduced progression to insulin therapy. ${ }^{8}$ Vildagliptin, a DPP-4 inhibitor, increases the proportion of active GLP-1 by inhibiting DPP-4 enzyme. ${ }^{6}$ Vildagliptin along with other DPP-4 inhibitors is known to improve glycemic control, by reducing fasting plasma glucose levels, postprandial glucose levels, $\mathrm{HbA}_{1 \mathrm{c}}$ levels without weight gain and with an apparently benign adverse event profile. ${ }^{9}$ The current open label 12-week study compared the efficacy of pioglitazone or vildagliptin as add-on therapy in patients who had poor glycemic control with combination therapy of metformin plus sulfonylurea.

\section{MATERIALS AND METHODS}

\section{Setting and patient eligibility}

This was an open labeled, prospective study conducted in Endocrinology Outpatient Department (OPD) in Dayanand Medical College and Hospital, Ludhiana, India. A total of 50 patients with Type 2 DM, age $>30$ and $\leq 70$ years of either gender were included in the study. Other inclusion criteria were: patients taking a combination of metformin + sulfonylurea (glibenclamide or glipizide or gliclazide or glimepride) for at least 3 months with uncontrolled hyperglycemia i.e. $\mathrm{HbA}_{1 \mathrm{c}}>7 \% \leq 11 \%$ and Body Mass Index (BMI) $>25 \mathrm{~kg} / \mathrm{m}^{2}$. Pregnant and lactating females, patients on insulin therapy, history of type $1 \mathrm{DM}$, signs of diabetic complications (nephropathy, neuropathy and retinopathy), and patients with clinical signs and symptoms of acute myocardial infarction, liver failure, chronic heart failure and renal failure were excluded. The study was approved by the Institutional Ethics Committee. A written informed consent was obtained from all the patients preceding the beginning of the study. The clinical study is registered with Clinical Trials Registry of India, no. CTRI/2013/04/003582.

\section{Intervention}

The patients were randomly assigned on a 1:1 basis to receive either pioglitazone or vildagliptin ( $\mathrm{n}=25 \mathrm{each})$. The patients in the first group received pioglitazone $(30 \mathrm{mg}$ once daily) and those in second group received vildagliptin (50 $\mathrm{mg}$ twice daily) in addition to the earlier treatment with metformin and sulfonylurea. The patients were advised to continue with the lifestyle modifications including daily moderate exercise (around 150 minutes/week) and controlled diet.

\section{Clinical response assessment}

The efficacy of pioglitazone and vildagliptin was assessed by measuring the change in the $\mathrm{HbA}_{1 \mathrm{c}}$ and fasting plasma glucose (FPG) levels after 12 weeks of treatment. Fasting plasma glucose and $\mathrm{HbA}_{1 \mathrm{c}}$ levels were measured at baseline and at 12 weeks. Primary end point was change in $\mathrm{HbA}_{1 \mathrm{c}}$ levels at 12 weeks as compared to the baseline levels in both the groups. The secondary end points were change in FPG levels at 12 weeks as compared to baseline levels and the percentage of patients with $\mathrm{HbA}_{1 \mathrm{c}}<7 \%$ at 12 weeks.

Along with, the serum creatinine, serum bilirubin levels, aminotransferases and alkaline phosphatase levels were measured both at baseline and after 12 weeks. The patients were instructed to report any adverse event appreciated by them. They were informed about the risk of development of some cardiovascular symptoms related to congestive heart failure.

The results were expressed as mean $\pm \mathrm{SD}$. The data was analyzed by unpaired t test. A value of $p<0.05$ was considered as statistically significant.

\section{RESULTS}

\section{Patient baseline characteristics}

The patients $(\mathrm{n}=50)$ were equally divided into two groups with similar gender distribution [(group I; males 10, females 15), (group II; males 11 and females 14)]. The 
baseline characteristics were similar between the two groups. The $\mathrm{HbA}_{1 \mathrm{c}}$, FPG and random plasma glucose (RPG) levels were not statistically different between the two groups (Table 1).

\section{Glycemic control}

$H b A_{1 c}$ levels

The mean $\mathrm{HbA}_{1 \mathrm{c}}$ levels at the beginning of the study were $10.95 \pm 2.9 \%$ and $11.3 \pm 0.6 \%$ in pioglitazone and vildagliptin groups respectively. At study end, $\mathrm{HbA}_{1 \mathrm{c}}$ levels were reduced from baseline by $1.65 \%$ in the pioglitazone group and by $1.23 \%$ in the vildagliptin group $(\mathrm{p}<0.001$ for both groups). But, this reduction was statistically nonsignificant between the two groups $(p=0.16)$ (Figure 1). Only four patients out of a total of 50 , showed $\mathrm{HbA}_{1 \mathrm{c}}<7 \%$ at 12 weeks, out of which three were from pioglitazone group and one from vildagliptin group.

\section{Fasting plasma glucose levels}

FPG levels decreased significantly from baseline to the end of study in both groups $(\mathrm{p}<0.001)$; and the reductions were not statistically different in both the groups $(p=0.074)$ (Figure 2). Also, there was a non-significant difference in mean FPG levels at 12 weeks $(p=0.061)$. Similarly, the

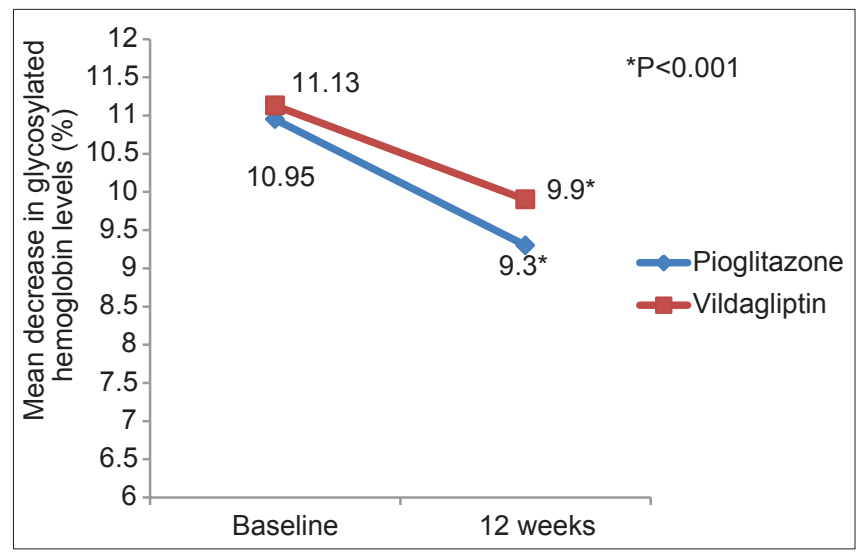

Figure 1: Mean decrease in $\mathrm{HbA1c}$ levels after twelve weeks of study.

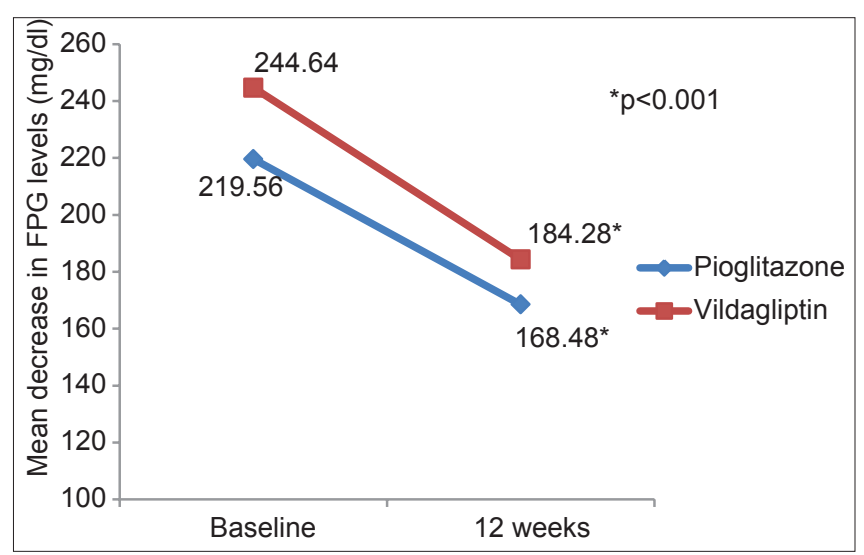

Figure 2: Mean decrease in FPG levels after 12 weeks reduction in RPG levels was significant in both the groups $(p<0.001)$, but with no statistical difference in the decrease in both the groups $(\mathrm{p}=0.40)$.

None of the patients reported any adverse event during the study period. There was a non significant change in the levels of serum creatinine, AST, ALT and ALP enzymes in both the groups as compared to baseline (Table 2).

\section{DISCUSSION}

This study evaluated two different add-on therapies among patients having inadequately controlled Type $2 \mathrm{DM}$ even after treatment with dual therapy of metformin and sulfonylurea. The results suggest that both vildagliptin and pioglitazone led to a significant decrease in $\mathrm{HbA}_{1 \mathrm{c}}$ and FPG levels after 12 weeks of treatment. There was a non-significant difference between the two groups with reference to reduction in $\mathrm{HbA}_{1 \mathrm{c}}$, FPG and RPG levels. More patients ( 3 out of 4 ) from the pioglitazone group achieved the target of $\mathrm{HbA}_{1 \mathrm{c}}<7 \%$ during the study period. The evaluation of the primary end point ( $\mathrm{HbA}_{1 \mathrm{c}}$ levels), shows no significant difference in the efficacy of both the drugs as there was a non significant difference in the mean reduction in $\mathrm{HbA}_{1 \mathrm{c}}$ levels.

Inadequate glycemic control among patients with $\mathrm{DM}$ is a major public health problem. According to the ADA 2012 guidelines, patients who are inadequately controlled with metformin and sulfonylurea combination, can be prescribed an additional third drug (one drug from the following groups- thiazolidinediones, DPP-4 inhibitors or GLP-1

\section{Table 1: Baseline characteristics of patients}

\begin{tabular}{lcc}
\hline Parameters & Pioglitazone group & Vildagliptin group \\
\hline Age (years) & $54.84 \pm 8.62$ & $58.08 \pm 7.97$ \\
FPG (mg/dl) & $219.56 \pm 30.70$ & $244.64 \pm 27.90$ \\
RPG (mg/dl) & $302.72 \pm 37.20$ & $316.88 \pm 30.30$ \\
$\mathrm{HbA}_{1 \mathrm{c}}(\%)$ & $10.95 \pm 2.8$ & $11.03 \pm 0.06$ \\
$\mathrm{AST}^{\mathrm{m}}$ & $13.04 \pm 1.79$ & $12.52 \pm 2.14$ \\
$\mathrm{ALT}$ & $10.56 \pm 1.85$ & $10.84 \pm 2.03$ \\
ALP & $9.24 \pm 1.79$ & $9.68 \pm 1.73$
\end{tabular}

Values mean \pm SD. FPG: Fasting plasma glucose, $\mathrm{HbA}_{1 \mathrm{c}}$ Glycosylated hemoglobin, RPG: Random plasma glucose, AST: Asparate transaminase, ALT: Alanine aminotransaminase, ALP: Alkaline phosphatase

\section{Table 2: Enzyme levels at twelve weeks}

\begin{tabular}{lcc}
\hline Enzymes & Pioglitazone group & Vildagliptin group \\
\hline Serum creatinine & $0.73 \pm 0.16$ & $0.74 \pm 0.12$ \\
(mg/dl) & $12.16 \pm 2.23$ & $12.72 \pm 1.90$ \\
AST & $10.68 \pm 2.15$ & $10.68 \pm 1.79$ \\
ALT & $9.72 \pm 1.77$ & $9.12 \pm 1.56$ \\
ALP &
\end{tabular}

Values mean $\pm S D$; AST: Asparate transaminase, ALT: Alanine aminotransaminase, ALP: Alkaline phosphatase 
receptor agonists). ${ }^{5}$ There are some comparative clinical studies for the choice of the second or third drug among such patients. Roberts VL et al, 2005 found that the addition of glimepride significantly improved the glycemic control as compared to placebo with an acceptable tolerability profile, among patients with type $2 \mathrm{DM}$ not adequately controlled by dual therapy of metformin and thiazolidinedione. ${ }^{10}$ The results by Bell DS et al, 2011 show that a fixed dose triple oral diabetes polypill containing glimepride, metformin SR (500 mg) and pioglitazone (15 mg) led to a lower $\mathrm{HbA}_{1 \mathrm{c}}$ levels as compared to combination of human insulin 70/30 mix and $500 \mathrm{mg}$ metformin among patients with type $2 \mathrm{DM}$ inadequately controlled on combination of glimepride and metformin. ${ }^{11}$ In a comparison using historical control, Hsia SH et al, 2011 compared the efficacy of sitagliptin $100 \mathrm{mg}$ daily among patients with poorly controlled type $2 \mathrm{DM}$ while taking maximum tolerated doses of metformin plus sulfonylureas, with historical control group of similar patients treated with rosiglitazone, $8 \mathrm{mg}$ daily, or pioglitazone, $45 \mathrm{mg}$ daily, as their third-line oral agent. Although, $\mathrm{HbA}_{1 \mathrm{c}}$ was reduced in both groups at four months $(p<0.001)$, the reduction of $\mathrm{HbA}_{1 \mathrm{c}}$ levels and the percentage of patients who achieved $\mathrm{HbA}_{1 \mathrm{c}}$ levels $<7.5 \%$ was greater with thiazolidinediones than with sitagliptin ( $p=0.006$ and $p=0.026$ ). The third-line add-on therapy with a thiazolidinedione, controlled hyperglycemia more effectively than sitagliptin after four months of use. ${ }^{12}$ Rosenstock J et al, 2006 evaluated the efficacy and safety of insulin glargine and rosiglitazone among patients on metformin and sulfonylurea. The $\mathrm{HbA}_{1 \mathrm{c}}$ improvements were similar in both the groups, but when baseline was more than $9.5 \%$, insulin glargine led to a greater improvement as compared to rosiglitazone $(\mathrm{p}<0.05)$. Insulin glargine had less weight gain than rosiglitazone, fewer adverse events, and no peripheral edema. ${ }^{13}$

Similarly, both vildagliptin and pioglitazone have also been evaluated for their use as second or third choice drugs among the patients with inadequate control with the previous therapy. Rodriquez A et al, 2008 conducted an observational cohort clinical study in which patients were started on pioglitazone plus a sulfonylurea, pioglitazone plus metformin or a sulfonylurea plus metformin due to inadequate control with previous therapy. In all the groups, there was an increase in serum high density lipoproteincholesterol (HDL-C) and decrease in triglyceride levels and the inter-group differences were significant $(p<0.001$ in both parameters). The mean FPG and $\mathrm{HbA}_{1 \mathrm{c}}$ reductions were significantly greater in the pioglitazone cohorts. ${ }^{14}$ Bolli $\mathrm{G}$ et al, 2008 compared vildagliptin $50 \mathrm{mg}$ twice daily $(\mathrm{n}=295)$ and pioglitazone $30 \mathrm{mg}$ daily $(\mathrm{n}=281)$ among patients with inadequate glycemic control $\left(\mathrm{HbA}_{1 \mathrm{c}}-7.5-\right.$ $11 \%$ ) receiving a stable dose of metformin $\geq 1500 \mathrm{mg}$ in a randomized active-controlled study of 52 weeks duration.
Their primary objective was to determine non-inferiority of vildagliptin at 24 weeks with respect to change in $\mathrm{HbA}_{1 \mathrm{c}}$ levels from baseline. During the following period of 28 weeks, the long-term safety, the mean change in $\mathrm{HbA}_{1 \mathrm{c}}$ and FPG levels and body weight as compared to baseline were assessed. Non-inferiority of vildagliptin to pioglitazone was established in lowering $\mathrm{HbA}_{1 \mathrm{c}}$ levels, with a noninferiority margin of $0.3 \%$ (between-group difference $=$ $0.1 \%$ ) during the first 24 weeks. During the remaining 28 weeks, comparable $\mathrm{HbA}_{1 \mathrm{c}}$ decreases were recorded in both groups. Vildagliptin provided additional lowering of $\mathrm{HbA}_{1 \mathrm{c}}$ to that achieved with metformin alone and comparable to that achieved with pioglitazone, but weight gain was seen with pioglitazone $(+2.6 \mathrm{~kg}))^{15,16}$ Rosenstock J and Fitchet M, 2008 also mention a comparison of vildagliptin $50 \mathrm{mg}$ twice daily and pioglitazone $30 \mathrm{mg}$ daily in patients inadequately controlled with ongoing metformin therapy. Compared with add-on pioglitazone, vildagliptin reduced HbA1c by $0.9 \%$ vs. $1.0 \%$ and was not associated with weight gain $(+0.3 \mathrm{~kg}$ vs. $+1.9 \mathrm{~kg})$ over 24 weeks. ${ }^{17}$ Similarly, the results of our study show that both the drugs led to a significant decrease in all the parameters of glycemic control i.e. $\mathrm{HbA}_{1}$, FPG and RPG levels. During our review, we could not find any published clinical study comparing these two drugs among patients with type $2 \mathrm{DM}$ inadequately controlled with monotherapy or dual combination therapy, in the Indian population. As the results show that both vildagliptin and pioglitazone have similar efficacy, the cost of vildagliptin can be a limiting factor for its wider use in India. An economic analysis can help in evaluating these two drugs.

Although both the drugs have proven efficacy for lowering $\mathrm{HbA}_{1 \mathrm{c}}$ and FPG levels, yet these are still being evaluated for other beneficial or harmful effects. The PROactive study showed that pioglitazone increased the incidence of heart failure with a relative risk of $1.5 \% \cdot{ }^{8,18}$ Meta-analysis and multiple randomized controlled trials of DPP-4 inhibitors are still undergoing to understand the cardiovascular effects. ${ }^{19}$ In this study, as the number of patients was small and they were studied for a short duration, the probability of recording the adverse effects was less. None of the patients reported any adverse effect. The known adverse effects of pioglitazone are weight gain, edema, and increased risk of congestive heart failure, increased risk of bone fracture among women and lowering of transaminases levels. On the other hand, the long term clinical studies with vildagliptin have shown mild and transient adverse effects like dizziness, headache and rare cases of hepatitis and angioedema. ${ }^{6,20}$

Limitations of the study include the small number of patients and the short duration of the study. Although the measurement of $\mathrm{HbA}_{1 \mathrm{c}}$ levels after 12 weeks shows 
the glycemic variability during this period, a study of longer duration can also help us in evaluating the efficacy of vildagliptin and pioglitazone in combination with metformin and sulfonylurea. We plan to continue the same protocol in a larger group of patients so as to compare both the safety and efficacy of the two drugs. The results of the study show that both pioglitazone and vildagliptin provided additional $\mathrm{HbA}_{1 \mathrm{c}}$ lowering to that achieved with combination of metformin and sulfonylurea. Both pioglitazone and vildagliptin demonstrated similar efficacy when added to metformin and sulfonylureas for three months.

\section{REFERENCES}

1. International Diabetes Federation. IDF Diabetes Atlas, 6th edn. Brussels, Belgium: International Diabetes Federation, 2013. http://www.idf.org/diabetesatlas.

2. Ramachandran A, Snehalatha C, Samith Shetty A and Nanditha A. Trends in prevalence of diabetes in Asian countries. World J Diabetes 2012;3(6):110-117.

3. Pradeepa R, Deepa R and Mohan V. Epidemiology of diabetes in India--current perspective and future projections. J Indian Med Assoc 2002; 100(3):144-148.

4. Derosa $G$ and Sibilla S. Optimizing combination treatment in the management of type 2 diabetes. Vasc Health Risk Manag 2007; 3(5):665-671.

5. Inzucchi SE, Bergenstal RM, Buse JB, Diamant M, Ferrannini $\mathrm{E}$, Nauck $\mathrm{M}$, et al. Management of hyperglycaemia in type 2 diabetes: a patient-centered approach. Position statement of the American Diabetes Association (ADA) and the European Association for the Study of Diabetes (EASD). Diabetologia 2012;55(6):1577-1596.

6. Powers AC and D'Alessio D. Endocrine Pancreas and Pharmacotherapy of diabetes mellitus and hypoglycemia. In Goodman and Gilman's The Pharmacological Basis of Therapeutics $12^{\text {th }}$ edition. Edited by Brunton LL, Chabner BA, Knollman BC. New York: McGraw Hill Publishers; 2011:12371274.

7. Derosa G. Efficacy and tolerability of pioglitazone in patients with type 2 diabetes mellitus: comparison with other oral antihyperglycemic agents. Drugs 2010;70(15):1945-1961.

8. Scheen AJ, Tan MH, Betteridge DJ, Birkeland K, Schmitz $\mathrm{O}$ and Charbonnel B; PROactive investigators. Long term glycaemic control with metformin-sulphonylurea-pioglitazone triple therapy in PROactive (PROactive 17). Diabet Med 2009; 26(10):10331039.

9. Deacon CF. Dipeptidyl peptidase-4 inhibitors in the treatment of type 2 diabetes: a comparative review. Diabetes Obes Metab 2011; 13(1):7-18.

10. Roberts VL, Stewart J, Isse M, Lake B and Melis R. Triple therapy with glimepiride in patients with type 2 diabetes mellitus inadequately controlled by metformin and a thiazolidinedione: results of a 30-week, randomized, double-blind, placebocontrolled, parallel-group study. Clin Ther 2005;27(10):15351547.

11. Bell DS, Dharmalingam M, Kumar S and Sawakhande RB. Triple oral fixed-dose diabetes polypill versus insulin plus metformin efficacy demonstration study in the treatment of advanced type 2 diabetes (TrIED study-II). Diabetes Obes Metab 2011; 13(9):800-805.

12. Hsia SH, Nayar MD, Duran $P$, Shaheen M and Davidson MB. Sitagliptin compared with thiazolidinediones as a third-line oral antihyperglycemic agent in type 2 diabetes mellitus. Endocr Pract 2011;17(5):691-698.

13. Rosenstock J, Sugimoto D, Strange P, Stewart JA, Soltes-Rak E and Daliey G. Triple Therapy in Type 2 Diabetes. Diabetes Care 2006;29(3):554-559.

14. Rodriquez A, Reviriego J, Polavieja P and Mesa J. Six-month effectiveness and tolerability of pioglitazone in combination with sulfonylureas or metformin for the treatment of type 2 diabetes mellitus. Med Clin (Barc) 2008;131(19):721-730.

15. Bolli G, Dotta F, Rochotte E and Cohen SE. Efficacy and tolerability of vildagliptin vs pioglitazone when added to metformin: a 24-week, randomized, double-blind study. Diabetes Obes Metab 2008;10(1):82-90.

16. Bolli G, Dotta F, Colin L, Minic B and Goodman M. Comparison of vildagliptin and pioglitazone in patients with type 2 diabetes inadequately controlled with metformin. Diabetes Obes Metab 2009;11(6):589-595.

17. Rosenstock $\mathrm{J}$ and Fitchet $\mathrm{M}$. Vildagliptin: Clinical trials programme in monotherapy and combination therapy for type 2 diabetes. Int J Clin Pract Suppl 2008;159:15-23.

18. Aljada A, Shah KA and Mousa SA. Peroxisome ProliferatorActivated Receptor Agonists: Do They Increase Cardiovascular Risk? PPAR Research vol. 2009, Article ID 460764, 7 pages, 2009. doi:10.1155/2009/460764.

19. Jose T and Inzucchi SE. Cardiovascular effects of the DPP-4 inhibitors. Diab Vasc Dis Res 2012;9(2):109-116.

20. Galvus monograph. Available from: URL: http://www.ema. europa.eu/docs/en_GB/document_library/EPAR_-_Product_ Information/human/000771/WC500020327.pdf (accessed on 11th January, 2014).

\section{Authors Contribution:}

KK - designed and conducted the study, drafted the manuscript; RK - designed and conducted the study; NM - designed and conducted the study; SA - designed the study, analysed the data, drafted the manuscript, SK - designed the study, analysed the data and reviewed the manuscript.

Source of Support: Nil, Conflict of Interest: None declared. 